IJ§ER

ISSN: 2149-5939
International Journal of Social Sciences and Education Research

Online, http://dergipark.gov.tr/ijsser

Volume: 3(3), 2017

\title{
Üniversite öğrencilerinin toplumsal cinsiyet rolleri tutumlarına yönelik bir araştırma: Ege Üniversitesi İletişim Fakültesi örneği
}

\section{A study oriented on the communication faculty students' attitudes towards gender roles: Ege University sample}

\author{
Aslı Elgün $^{1} \quad$ Mine Yeniçeri Alemdar ${ }^{2}$
}

Received Date: $20 / 03 / 2017$

Accepted Date: $10 / 06 / 2017$

$\ddot{\boldsymbol{O} z}$

Bu çalışma, gelecekte medya sektöründe yer alacak olan ve iletişim eğitimi alan ö̆grencilerin toplumsal cinsiyet rollerine yönelik tutumlarını ölçmek üzere tasarlanmıştır. Medya sektörünün çeşitli alanlarında istihdam edilme olasılıkları yüksek olan iletişim fakülttesi öğrencilerinin toplumsal cinsiyet rollerine ilişkin tutumlarının, medya sektöründe cinsiyetçi bakış açılarının ortadan kalkmasında, istidama ilişkin eşitliğin tesis edilmesinde ve basmakalıp yargılar çerçevesinde oluşan temsil sisteminin dönüşmesinde etkili olacağı düşünülmektedir. Bu bağlamda, çalışmada İletişim Fakültesi öğrencilerinin toplumsal cinsiyet rollerine yönelik tutumları, Simge Zeyneloğlu tarafindan 2008 yılında gelistirilen "Toplumsal Cinsiyet Rolleri Tutum Ölçeği” kullanılarak tespit edilmeye çalışlacaktır. Ege Üniversitesi İletişim Fakültesi 1. Sinif öğrencileri ile 4. sinif öğrencilerine uygulanacak olan anket çalışması aracılığıyla toplumsal cinsiyet rollerine yönelik geleneksel kadın/erkek cinsiyet rollerine bakış açılarının ortaya konması hedeflenmektedir. Araştırmada aynı zamanda demografik sorular aracılı̆̆ıyla, öğrenci demografileri ile toplumsal cinsiyet rolleri tutumları arasındaki ilişkiler tanımlanacaktır.

Anahtar sözcükler: Toplumsal cinsiyet, medya, iletişim fakültesi

\begin{abstract}
This study is designed to measure media and communication students' attitudes towards gender roles. The attitudes of media and communication faculty students who have a higher prospect of being employed in various parts of the media industry, is thought to be influential in removing the sexist perspectives in the media industry, in providing equality with regard to employment and in transforming the representation system that formed in the framework of stereotypical judgements. In this context, Communication Faculty students' attitudes towards gender roles are going to be analyzed by using "Gender Roles Attitude Scale", developed by Simge Zeyneloğlu in 2008. With the help of a questionnaire that is going to be given to Ege University Communication Faculty first and final year students, perspectives on traditional malelfemale gender roles towards gender roles are intended to be revealed. Also with the help of demographic questions in the study, relations between student demographics and gender role attitudes are going to be defined.
\end{abstract}

Keywords: Gender, media, faculty of communication

\section{Giriş}

20. yüzyılın en önemli tartışmalarının başında medya ve toplum ilişkisi gelmektedir. Medya gerçekten de topluma etki etmekte midir, medyanın toplumu yönlendirici bir gücü var mıdır, kimliğin ve cinsiyetin inşasında medya etkili midir toplum mu medyayı belirler gibi sorular küreselleşen dünyada halen güncelliğini korumakta ve üzerinde araştırmaların devam ettiği bir alan olarak karşımıza çıkmaktadır. Bu sorular temelde iki aks üzerinden ilerlemektedir, kitle iletişim araçlarının yarattığı kültür bireyi, toplumu şekillendirmektedir, etkilemektedir yaklaşımların birini

${ }^{1}$ Ege Üniversitesi, İzmir, TURKEY
${ }^{2}$ Ege Üniversitesi, İzmir, TURKEY 
Elgün, A., Yeniçeri Alemdar, M. (2017). A study oriented on the communication faculty students' attitudes towards gender roles: Ege University sample. International Journal of Social Sciences and Education Research, 3(3), 1054-1067.

oluştururken; toplumun kitle iletişim araçlarını yönlendirme, şekillendirme gücü ise ikinci yaklaşımı oluşturmaktadır.

Kitle iletişim araçlarını ister tek taraflı, izleyiciyi pasif gören yaklaşımlardan ele alalım istersek izleyiciyi bu iletişim sürecinde aktif gören modellerden hareketle ele alalım, bu süreç bireyin ve toplumun davranışlarını, yapısını (çoğu zaman örtük biçimlerde) şekillendirme, yeniden üretme gücüne sahip bir araç olarak değerlendirilmektedir. "Kitle iletişimi egemen düşünceleri ve ideolojik pratikleri desteklemekte ve yeniden üretmektedir ve kültürün üretimi ve dağıtımında önde gelen araçlar ve kanallar haline gelmişlerdir; bunun sonucunda insanlar kendine ve dış dünyaya ait gerçekleri, deneyimleri burada üretilen bilgiden öğrenir ve kavrar" (Erdoğan\& Alemdar,2002, ss.402-403). Metaforlar, metonimler, semboller, kahraman hikayeleri ile örtük bir biçimde üretilen bu anlamın içinde çeşitli ideolojiler saklıdır. Medya aracılıyla kültürlenen birey, bu mesajları içselleştirmekte ve doğallaştırmaktadır. Bu sürecin en önemli kısmını ise toplumsal cinsiyet rollerinin temsili ve yeniden üretim sürecidir. Yapılan araştırmalar göstermiştir ki medya toplumsal cinsiyet rollerini yeniden üreten en güçlü modern kurumlardan biridir. Bu süreç, iletişim sektöründe çalışan cinsiyetlendirilmiş bireylerin ürettiği metinler ve temsil sistemi ile tamamlanmakta ve yeniden üretilmektedir.

\section{Literatür}

\section{Cinsiyet, toplumsal cinsiyet kavramlart üzerine}

16. yüzyılda Birinci Dalga Feminist akım kadınların siyasal anlamda özgürleşmesine yönelik adımlar atmış ardından da 1960'lı yıllarda etkisini gösteren İkinci Dalga Feminizm kadın ve erkek çalışmalarına yeni boyutlar kazandırmıştır. Bu boyutlardan en önemlisi toplumsal cinsiyet kavramının ortaya çıkmasıdır.

Cinsiyet anatomik ve fizyolojik farkl1l1klara gönderme yapan bir kavramdır. Cinsiyet terimi bağımsız bir değişken olarak kullanıldığında bireyin genetik ve kromozomal birleşimine, içsel ve dışsal üreme organlarına ve bir cinsiyeti diğer cinsiyete oranla önemli ölçüde farklılaştıran ikincil düzeydeki cinsel karakteristiklere ya da kısacası bir bireyin biyolojik cinsiyetine gönderimde bulunmaktadır" (Girginer, 1994, 7). Toplumsal cinsiyet ise erkek ve kadının biyolojik farklılaşmasına kültürler tarafından yüklenen anlamlar ve değerlerdir. Bu süreç, kurumlarla ve sosyal çevre ile karşılıklı, iç içe geçmiş, karışık ilişkiler bütünüdür. Toplumsal cinsiyet kültürün oluşturduğu farklı yaşam stillerinin, davranışların ve beklentilerin ve bireylerin eril ve dişil olarak kültürün keyfi kalıplarına göre ortalama olarak farklılaşma düzeylerinin araştırılmasına gönderimde bulunmaktadır (Girginer, 1994, s.8).

\section{Toplumsal cinsiyet rolleri ve kallpyargılar}

Sosyal rol, kişinin sosyalizasyon sürecinde başkalarını gözleyerek, taklit ederek edindiği örüntüler (Fichter, 2002, ss. 100-107) ya da "bir statü ile gelen davranış biçimi beklentileri" (Erdoğan\&Alemdar, 1990, s.29) olarak tanımlanmaktadır. Toplumsal cinsiyet rolü ise, erkek ve kadın olmanın anlamı, kişinin cinsiyeti ile belirlenen genel rolüdür ve kalıplaşmış beklentileri gösteren bir yapıya sahiptir (Connell, 1998, s.78). Toplumsal cinsiyet rolleri cinsiyetten ayrı düşünülemez. Bireyin içinde bulunduğu toplumun yapısına göre cinsiyetine yüklenen anlamlar, değerler, özellikler ve beklentiler olarak tanımlanan toplumsal cinsiyet rolleri, bireyin davranış ve tutumlarını yönlendirici olmaktadır ve toplum/kültür hem cinsiyet özelliklerine hem de toplumsal cinsiyet rollerine ilişkin kalıp yargılar üretmektedir. 
Elgün, A., Yeniçeri Alemdar, M. (2017). Üniversite öğrencilerinin toplumsal cinsiyet rolleri tutumlarına yönelik bir araştırma: Ege Üniversitesi İletişim Fakültesi örneği. International Journal of Social Sciences and Education Research, 3(3), 1054-1067.

Kalıp yargılar, sosyal bilimler alanında ilk olarak 1922 yılında Lippman tarafindan kullanılmış bir kavramdır ve belli bir gruba ilişkin bilgi, inanç ve beklentileri içeren değişmesi güç olan bilişsel yapıları içermektedir (Pilcher\&Whelehan, 2004, s.166). Cinsiyet rolleri kalıp yargıları psikolojik özelliklere vurgu yaparken toplumsal cinsiyet rollerine ilişkin kalıp yargılar ise, cinsiyete yüklenen sosyokültürel beklentileri kapsamaktadır. Bu kalıp yargılar toplumsal yapılar ve kültür içinde kadının ve erkeğin davranış biçimlerinden, eğitim yaşantısına kadar her alanda nasıl olması gerektiğine ilişkin beklentiler ve örüntülerle ilgilidir. Toplumsal cinsiyet rollerine ilişkin kalıp yargılar erkek ve kadına farklı görevler ve roller yüklemektedirler. $\mathrm{Bu}$, cinsiyete göre organize edilmiş olan kalıp yargılar, işbölümünden meslek seçimine, istihdam politikalarından aile içi ilişkilerin düzenlenmesine kadar her alanda görülmektedir. Toplumsallaşma sürecinde birey, bu kalıp yargılara göre biçimlenmekte ve olumlu/olumsuz yaptırımlar, yani davranışı ödüllendiren ya da kısıtlayan ve toplum tarafindan uygulanan güçler yoluyla yönlendirilmektedirler (Giddens, 2012, s.508). Toplumsal cinsiyet rolleri kalıp yargıları, kültüre, zamana ve toplumsal ilişkilere bağlı olarak farklı1ık gösterse de, genellenebilir bazı özellikler taşımaktadır. Geleneksel toplumsal cinsiyet rolleri kalıp yargılarına göre bakımla ve sevecenlikle ilişkilendirilen kadın, erkeklere sevgi sunmakta, bunun karşılığında ise iktidar ile ilişkilendirilen erkek evin geçimini sağlamakta ve aileyi koruma görevini üstlenmektedir (Hooks, 2016, s.124).

\section{Toplumsal cinsiyet rollerini etkileyen kurumlar}

Toplumsal cinsiyet rollerini üreten çeşitli toplumsal ve kültürel mekanizmalardan söz etmek mümkündür. Kavram temelde sosyal olarak inşa edilen, erkeklik ve dişiliği belirlemede, doğuştan getirilen bedensel farklılıklara bağlanamayan tüm etmenlerin, fakat özellikle de sosyal ve kültürel etmenlerin önemini vurgulamaktadır (Cevizci, 1999, s.849). Bu inşa sürecine etki eden yapılar arasında eğitim, aile, dil, din, kitle iletişim araçları bulunmaktadır. Bu kurumlar aynı zamanda bireyin tutumlarını da etkilemektedirler.

Toplumsal cinsiyet rollerini etkileyen kurumların başında aile gelmektedir. Çocuk doğduğu andan itibaren kı ya da erkek olmasına bağlı olarak cinsiyetlendirilmekte ve aile bu sürecin en önemli eyleyeni görevini üstlenmektedir. İki cinsiyet doğuştan itibaren önce farklı renklerde giydirilerek (örneğin, kızlar pembe, erkekler mavi), sonra farklı oyuncaklara yönlendirilerek (örneğin, kızlara bebek, erkeklere araba), farklı okulları seçmeleri için etkilenerek (örneğin, kızlar için sosyal bilimler ve edebiyat, erkekler için fen bilimleri ve mühendislik) cinsiyetlendirilmektedirler (Ecevit, 2011, s.5). Bu beklentiler çocukluk döneminden başlayarak yetişkinliğe kadar kişide toplumsal cinsiyet rollerine ilişkin tutumların oluşmasına neden olmaktadır.

Eğitim toplumsal cinsiyet rollerini yeniden üreten bir başka kurum olarak karşımıza çıkmaktadır. Eğitim ile toplumsal cinsiyet rolleri ilişkisini, rol model olarak eğitmenler, eğitim-öğretim materyallerindeki temsiller, okul içi pratikler olarak değerlendirebiliriz. Eğitim sürecinde toplumsal cinsiyet rolleri başta kitaplar ve eğitimde kullanılan materyaller üzerinden sunulmaktadır. $\mathrm{Bu}$ materyaller, genellikle kadın ve erkeğe yönelik kalıpyargıları barındırmaktadır, çocuk bu kalıpyargılara göre kadınlık ve erkeklik rollerini öğrenmektedir ki bu temsiller genellikle beyaz, heteroseksüel evli çocuk sahibi bireyler üzerinden kurulmaktadır (Burr, 2002, s.56).

Kitle iletişim araçlarında kadın ve erkek belli toplumsal cinsiyet kalıpyargılara göre temsil edilmekte ve bu da geleneksel rollerin yeniden üretilmesine neden olmaktadır. Goffman gazetelerde ve dergilerde yer alan reklamlarda kadının ve erkeğin temsilini analiz ettiği çalışmasında erkeklerin kadınlara ne yapacağını söyledikleri, yüksek statülü rollerde kadınlarınsa erkeğe tabi 
Elgün, A., Yeniçeri Alemdar, M. (2017). A study oriented on the communication faculty students' attitudes towards gender roles: Ege University sample. International Journal of Social Sciences and Education Research, 3(3), 1054-1067.

olduğu, aşağı pozisyonlarda resmedildiğini ortaya koymaktadır (Burr, 2002, s. 104). Berger ise, yağlıboya geleneği ile reklamdaki konuların kadınlar açısından benzerliklerini şöyle dile getirmektedir: "..... Kalıplaşmış kadın tiplerini gösteren pozlar: Dingin anne (Madonna), uçarı sekreter (kadın oyuncu, kralın metresi), kusursuz ev sahibesi (seyirci sahibin karıs1), cinsel nesne (Venüs, su perisi), vb., Kadın bacaklarının cinsellik açısından özellikle vurgulanması,..., Erkeklerin zenginliğini ve güçlülüğünü gösterecek biçimde duruşları..." (Berger, 1986, s.138). Buradan hareketle gerek kadın gerekse erkeğe ilişkin toplumsal cinsiyet rolleri kalıpyargıları belli tarihsel süreçlerde ve kültürlerde farklı maskeler altında yer alsa da, yeniden inşa edilmektedirler. Kitle iletişim araçlarının kalıpyargılara dayalı olarak toplumsal cinsiyet rollerini inşası cinsiyetler arasında eşitsizliği yaratması açısından önem taşımaktadır.

\section{Toplumsal cinsiyet rolleri tutumları ile ilgili yapılan çalışmalar}

Uluslararası alanda toplumsal cinsiyet rollerine yönelik tutumların önemli görülmesi ve araştırılmaya başlanması II. Dalga Feminist Hareketin toplumsal cinsiyet rollerinin kadın ve erkek arasındaki eşitsizliğin kaynaklarından biri olduğunun anlaşılmasına paralel olarak başlamaktadır.1972'de Spence ve Helmreich tarafından geliştirilen Kadınlara Yönelik Tutum Ölçeği, 1974'te Bem'in Cinsiyet Rolü Envanteri, 1978 yılında Spence ve Helmreich'in geliştirdikleri Kişisel Tutum Ölçeği ve 1978'de Doyle ve Moore'un Erkek Rolüne Yönelik Tutum Ölçeği (O’Neil vd., 1986, s.337) toplumsal yaşamda kadınlık ve erkeklik rolleri ve bireyin tutumlarının ölçümlenmeye başlandığı ilk çalışmalar olarak nitelendirilebilir. 1984 yılında cinsiyet rolü eşitliğini ölçen Beere'nin geliştirdiği Cinsiyet Rolü Eşitlik Ölçeği, geleneksel ve eşitlikçi tutumları ölçen Larsen ve Long (1988)'a ait Geleneksel Cinsiyet Rol Ölçeği, Glick ve Fiske tarafından geliştirilen Erkeklere Yönelik Tutum Envanteri(1999) ve yine aynı kişilerin 1996 yılında geliştirdikleri Ambivalan Cinsiyetçilik Envanteri (Mchugh\&Frieze, 1997, ss.6-7) geliştirilmiş olan ölçeklerden sadece birkaçıdır.

Ulusal alanyazında ise en çok kullanılan ölçek 2008 yılında Zeyneloğlu tarafından geliştirilmiş olan "Toplumsal Cinsiyet Rolleri Tutum Ölçeği” (TCRTÖ) dir. Bu ölçeğin kullanıldığı çok sayıda çalışma mevcuttur (Atış,2010; Arıc1,2011; Özcan,2012; Öngen\&Aytaç, 2013; Bekleviç, 2013; Türkmenoğlu 2016). Toplumsal cinsiyet tutumlarına ilişkin yapılan çalışmaların ağırlıkla tıp ve eğitim bilimleri alanında olduğu görülmektedir. Bu tutum araştırmaları sosyal bilimler alanı için de önem arz etmektedir.

\section{Araştırma}

\section{Araştırmanın konusu ve amacı}

Araştırma, toplumsal cinsiyet rollerinin üretildiği alanlardan biri olarak medya sektöründe, ilerleyen yıllarda istihdam edilme olasılığı yüksek olan ve iletişim eğitimi alan öğrencilerin toplumsal cinsiyet rollerine ilişkin tutumlarını ölçmek üzere tasarlanmıştır.

\section{Yöntem ve veri toplama aracı}

Öğrencilerinin toplumsal cinsiyet rollerine yönelik tutumları Zeyneloğlu (2008) tarafindan geliştirilen “Toplumsal Cinsiyet Rolleri Tutum Ölçeği” kullanılarak ölçümlenmiştir. Ölçek 5 boyut ve 38 maddeden oluşmaktadır. Ölçekte kadın cinsiyet rolü, evlilikte cinsiyet rolü, geleneksel cinsiyet rolü, eşitlikçi cinsiyet rolü boyutları 8 'er madde; erkek cinsiyet rolü boyutu 6 maddeden oluşmuştur. 
Elgün, A., Yeniçeri Alemdar, M. (2017). Üniversite öğrencilerinin toplumsal cinsiyet rolleri tutumlarına yönelik bir araştırma: Ege Üniversitesi İletişim Fakültesi örneği. International Journal of Social Sciences and Education Research, 3(3), 1054-1067.

\section{Evren ve örneklem}

Araştırma evreni Ege Üniversitesi İletişim Fakültesi 1. ve 4. sınıf öğrencileridir. Evrenin, üniversite eğitiminin ilk ve son yılındaki öğrencilerden oluşmasının nedeni, üniversite eğitimi ve toplumsal cinsiyet dersini almanın anlamlı bir farklılık oluşturup oluşturmadığını belirlemektir. Olasılığa dayalı örnekleme yöntemlerinden grup (küme) örneklemi seçilmiştirr. Örneklem büyüklüğ̈̈nün belirlenmesi amacıyla, farklı büyüklükteki evrenler için kuramsal örneklem büyüklükleri (\%95 kesinlik düzeyi) tablosu incelendiğinde (Anderson 1990’dan akt. Balcı, 200, s.107) 1000 ve 4999 arasındaki evren büyüklüğünde örneklem büyüklüğünün 277 olduğu görülmektedir. Ege Üniversitesi İletişim Fakültesi'nde 2016-2017 eğitim öğretim yllında öğrenim gören 1. ve 4 sınıf toplam öğrenci sayısı 1164'tür. 511 adet form analizler için kullanılmıştır. Araştırmada anket geri dönüş oranının \%83 olduğu görülmüştür. Geri dönüş oranı alan yazın çerçevesindedir (Büyüköztürk, 2005, s.147).

\section{Verilerin analizi}

Verilerin analizinde SPSS 17.0 istatistik programı kullanılmıştır. Aritmetik ortalama, standart sapma, frekans hesaplamaları yapılarak; güvenilirlik, bağımsız örneklem t-testi, bağımsız örneklem tek yönlü varyans analizi, Mann -Whitney U testi, Kruskal-Wallis H testlerive doğrulayıcı faktör analizi yapılmıştır.

\section{Bulgular}

Yapılan normal dağılım testinde 2 boyutun normal dağılım göstermediği (Evlilikte CR-Eşitlikçi CR) görülmüştür. Normal dağılım göstermeyen boyutlara parametrik olmayan testler; normal dağılım gösteren boyutlara ise parametrik testler uygulanmıştır.

Ölçeğin güvenilirliğini test etmek amacıyla güvenilirlik analizi yapılmıştır. Güvenilirlik katsayısının 0.70 veya daha yüksek olması, yeterli olarak değerlendirilmektedir (Nunnally, 1978). Cronbach's Alpha ,791 olarak hesaplanmıştır.

Araştırmada kullanılan ölçek Türkiye'de üniversite öğrencileri örnekleminde geliştirilmiş olduğu için doğrulayıcı faktör analizi kullanılmıştır. Madde yükleri ve t değerlerinin öngörülen sınırlar içinde (0.30) gerçekleştiği görülmüş, yalnızca bir madde (Bir genç kızın, flört etmesine ailesi izin vermelidir), öngörülen değerlerin altında bir skora sahip olmuş, bu konuda uzman görüşüne başvurularak, maddenin soru formunda kalmasına karar verilmiştir. 
Elgün, A., Yeniçeri Alemdar, M. (2017). A study oriented on the communication faculty students' attitudes towards gender roles: Ege University sample. International Journal of Social Sciences and Education Research, 3(3), 1054-1067.

Tablo 1. Standardize edilmiş madde yükleri ve t değerleri

\begin{tabular}{|c|c|c|c|c|}
\hline Faktörler & Ortalama & $\begin{array}{c}\text { Standart } \\
\text { Sapma }\end{array}$ & $\begin{array}{l}\text { Madde } \\
\text { yükü }\end{array}$ & t değeri \\
\hline \multicolumn{5}{|c|}{ Kadın CR } \\
\hline 1 & 4.28 & 1.104 & 0.69 & 16.75 \\
\hline 2 & 1.57 & 0.949 & 0.52 & 11.69 \\
\hline 3 & 1.79 & 1.112 & 0.51 & 11.60 \\
\hline 4 & 3.77 & 1.437 & 0.21 & 4.35 \\
\hline 5 & 1.60 & 1.113 & 0.54 & 12.16 \\
\hline 6 & 2.19 & 1.293 & 0.64 & 15.10 \\
\hline 7 & 1.89 & 1.189 & 0.66 & 15.80 \\
\hline 8 & 1.60 & 0.999 & 0.56 & 12.93 \\
\hline \multicolumn{5}{|c|}{ Evlilikte CR } \\
\hline 9 & 1.41 & 0.838 & 0.73 & 18.45 \\
\hline 10 & 1.28 & 0.737 & 0.79 & 20.86 \\
\hline 11 & 1.32 & 0.765 & 0.82 & 22.14 \\
\hline 12 & 1.36 & 0.793 & 0.75 & 19.45 \\
\hline 13 & 1.20 & 0.627 & 0.71 & 17.99 \\
\hline 14 & 1.26 & 0.690 & 0.67 & 16.68 \\
\hline 15 & 1.83 & 1.249 & 0.35 & 7.74 \\
\hline 16 & 1.41 & 0.840 & 0.61 & 14.68 \\
\hline \multicolumn{5}{|c|}{ Geleneksel CR } \\
\hline 17 & 1.69 & 1.041 & 0.55 & 12.94 \\
\hline 18 & 1.36 & 0.810 & 0.65 & 15.78 \\
\hline 19 & 1.85 & 1.119 & 0.68 & 16.88 \\
\hline 20 & 1.68 & 1.120 & 0.78 & 20.18 \\
\hline 21 & 1.73 & 1.083 & 0.70 & 17.31 \\
\hline 22 & 2.11 & 1.264 & 0.65 & 15.76 \\
\hline 23 & 1.59 & 0.944 & 0.72 & 18.18 \\
\hline 24 & 1.71 & 1.028 & 0.64 & 15.64 \\
\hline \multicolumn{5}{|c|}{ Evlilikte CR } \\
\hline 25 & 4.57 & 1.042 & 0.71 & 18.06 \\
\hline 26 & 4.51 & 0.979 & 0.72 & 18.43 \\
\hline 27 & 4.66 & 0.902 & 0.83 & 22.74 \\
\hline 28 & 4.52 & 1.011 & 0.74 & 19.25 \\
\hline 29 & 4.57 & 0.961 & 0.84 & 23.07 \\
\hline 30 & 4.66 & 0.851 & 0.92 & 27.02 \\
\hline 31 & 4.46 & 1.051 & 0.72 & 18.38 \\
\hline 32 & 4.66 & 0.892 & 0.83 & 22.98 \\
\hline \multicolumn{5}{|l|}{ Erkek CR } \\
\hline 33 & 1.52 & 0.885 & 0.53 & 12.16 \\
\hline 34 & 1.25 & 0.601 & 0.68 & 16.61 \\
\hline 35 & 1.56 & 0.955 & 0.76 & 19.45 \\
\hline 36 & 1.45 & 0.855 & 0.82 & 21.47 \\
\hline 37 & 1.22 & 0.687 & 0.63 & 14.94 \\
\hline 38 & 1.81 & 1.125 & 0.58 & 13.40 \\
\hline
\end{tabular}


Elgün, A., Yeniçeri Alemdar, M. (2017). Üniversite öğrencilerinin toplumsal cinsiyet rolleri tutumlarına yönelik bir araştırma: Ege Üniversitesi İletişim Fakültesi örneği. International Journal of Social Sciences and Education Research, 3(3), 1054-1067.

Tablo 2. DFA uyum indeksleri

\begin{tabular}{|c|c|c|c|c|c|c|}
\hline $\mathbf{X}^{2} / \mathbf{s d}$ & $\mathbf{p}$ & RMSEA & CFI & AGFI & NFI & GFI \\
\hline 2.919 & 0.000 & 0.061 & 0.957 & 0.872 & 0.916 & 0.921 \\
\hline
\end{tabular}

Araştırmaya katılan öğrencilerin \%43.6'sı kadın, \%36'sı erkeklerden oluşmuştur. Aile gelirinde dikkat çekici nokta \%46'sının ortalama aile gelirinin 1500-3000 arasında oluşudur. Öğrencilerin ilköğrenimlerini bitirinceye kadar en uzun yaşadıkları yerleşim yeri sırasıyla il, ilçe ve köy olmuştur. Coğrafi bölge incelendiğinde en yüksek oranın \%40.9 ile Ege Bölgesi olduğu, en düşük bölgelerin Doğu Anadolu (\%3.3) ve Güney Doğu Anadolu (\%3.9) olduğu görülmüştür. Öğrencilerin \%74.6'sının aile tipi çekirdek ailedir. Bu durumu sırasıyla anne-babanın ayrı oluşu (11.9) ve geniş aile (7.8) izlemektedir.

Araştırmada öğrenci demografilerinden anne-baba öğrenim durumu ve anne-baba mesleği incelendiğinde ise anne öğrenim durumunda ilk okul mezunu (\%29.9) olma en; babada ise lise mezuniyeti (\%32.7) en yüksek yüzdeye sahip olmuştur. Katılımcıların \%53.8'inin annesi çalışmamakta (ev hanımı), \% 58.7' sinin babası ise serbest meslekte en yüksek frekansa sahip olmaktadır.

H1'i test etmek amacıyla; öğrencinin kaçıncı sınıfta olduğu (1-4) ve boyutlara yönelik tutumları arasındaki farklılaşmayı gösteren ortalama değerler ile standart sapma hesapları Tablo 3 'te sunulmuştur.

H1: Öğrencilerin 1. ve 4. sınıfta olmaları ile TCRTÖ'de yer alan boyutlara ilişkin tutumlarının farklılık göstermesi arasında anlamlı bir ilişki vardır.

Tablo 3. Sinıf bazında ortalama puan farklılıkları

Normal dağılım gösteren boyutlar

\begin{tabular}{|l|l|l|l|}
\hline Boyutlar & \multicolumn{1}{|c|}{$\begin{array}{c}1 \\
\text { Ort/ SS }\end{array}$} & \multicolumn{1}{c|}{$\begin{array}{c}\mathbf{1} \\
\text { Ort } / \mathbf{S S}\end{array}$} & \multicolumn{1}{|c|}{$\mathbf{p}$} \\
\hline Kadın cinsiyet rolü & $2.36 / 0.49$ & $2.30 / 0.50$ & 0,179 \\
\hline Geleneksel cinsiyet rolü & $1,73 / 0.77$ & $1.70 / 0.75$ & 0,716 \\
\hline Erkek cinsiyet rolü & $1.46 / 0.64$ & $1.46 / 0.58$ & 0.99 \\
\hline
\end{tabular}

p)0.05 Anlamlı farklılık bulunmamaktadır.

Normal dağılım göstermeyen boyutlar

\begin{tabular}{|c|c|c|}
\hline Boyutlar & $\begin{array}{c}1 \\
\text { Mean Rank }\end{array}$ & $\begin{array}{c}4 \\
\text { MeanRank }\end{array}$ \\
\hline Evlilikte cinsiyet rolü* & 259.13 & 252.02 \\
\hline Eşitlikçi cinsiyet rolü* & 258.54 & 252.77 \\
\hline
\end{tabular}

Eşitlikçi CR (U: 31447.5; p >0.05), Evlilikte CR (U:31279; p >0.05) p $>0.05$. Anlamlı farklılık bulunmamaktadır.

*Mann-Whitney U testi uygulanmıştır.

Analizde öğrencilerin kaçıncı sınıfta olduklarının TCRTÖ'de yer alan boyutları algılamada bir farklılaşmaya yol açmadığı görülmüş ve H1 hipotezi doğrulanmamıştır. Bu nedenle bundan sonra uygulanacak analizlerde, sınıf farkı gözetilmeden 1.ve 4. sınıf öğrencileri birlikte ele alınmiştır. 
Elgün, A., Yeniçeri Alemdar, M. (2017). A study oriented on the communication faculty students' attitudes towards gender roles: Ege University sample. International Journal of Social Sciences and Education Research, 3(3), 1054-1067.

Tablo 4. Öğrencilerin TCRTÖ’de yer alan boyutlara ilişkin ortalama ve standart sapma degerleri

\begin{tabular}{|l|l|}
\hline Boyutlar & \multicolumn{1}{|c|}{ Ort/SS } \\
\hline Kadın CR & $2.33 / 0.50$ \\
\hline Evlilikte CR & $1.39 / 0.58$ \\
\hline Geleneksel CR & $1.72 / 0.76$ \\
\hline Eşitlikçi CR & $4.57 / 0.78$ \\
\hline Erkek CR & $1.46 / 0.62$ \\
\hline
\end{tabular}

Kadın CR, evlilikte CR, geleneksel CR ve erkek CR boyutlarından alınacak ortalama puanın 1'e yakınlığı, öğrencilerin eşitlikçi tutuma sahip oluşunu, 5'e yakınlığı ise geleneksel tutumu göstermektedir. Bu noktada öğrencilerin "kadın cinsiyet rolü” alt boyutunda geleneksel ve eşitlikçi tutum yapısına sahip olma açısından ortada yer aldığından, diğer boyutlarda ise eşitlikçi bir tutum içinde olduğundan bahsedilebilir. Diğer boyutların aksine eşitlikçi CR boyutundan alınacak ortalama değerin 1'e yakınlığı geleneksel, 5'e yakınlığı ise eşitlikçi tutum göstergesidir. Bu nedenle bu boyutta da öğrencilerin eşitlikçi bir tutuma sahip oldukları görülmüştür.

\section{Demografik özelliklere göre boyutları algılama}

Öğrencilerin demografik özelliklerine göre TCRTÖ’de yer alan boyutlara ilişkin tutumlarında bir değişim olup olmadığını test etmek amacıyla; normal dağılım gösteren boyutlar için bağımsız örneklem t- testi ve bağımsız örneklem tek yönlü varyans analizi yapılmıştır. Normal dağılım göstermeyen boyutlar için ise parametrik olmayan testlerden Mann-Whitney U Testi ve Kruskal Wallis H testi uygulanmıştır (Ural\&Kılıç, 2011, ss.271-273).

H2: Öğrencilerin cinsiyeti ile TCRTÖ’de yer alan boyutlara ilişkin tutumlarının farklılık göstermesi arasında anlamlı bir ilişki bulunmaktadır.

H2 doğrultusunda öğrencilerin TCRTÖ'de yer alan boyutlara ilişkin tutumlarında cinsiyete göre farklılaşma Kadın CR, Evlilikte CR, Geleneksel CR, Erkek CR ve Eşitlikçi CR boyutlarında istatistiki olarak $\mathrm{p}\langle 0.01$ düzeyinde anlamlı farklılık gözlenmiştir. Bu nedenle H2 hipotezi kabul edilebilecektir.

Tablo 5. Cinsiyete göre ortalama puan farklılıkları- Normal dağılım gösteren boyutlar

\begin{tabular}{|l|l|l|l|}
\hline Boyutlar & \multicolumn{1}{|c|}{$\begin{array}{c}\text { K } \\
\text { Ort/SS }\end{array}$} & \multicolumn{1}{c|}{$\begin{array}{c}\text { E } \\
\text { Ort /SS }\end{array}$} & sig \\
\hline Kadın cinsiyet rolü & $2.18 / 0.46$ & $2.49 / 0.49$ & .000 \\
\hline Geleneksel cinsiyet rolü & 1.38 & 2.00 & .000 \\
\hline Erkek cinsiyet rolü & 1.26 & 1.68 & .000 \\
\hline
\end{tabular}

$\mathrm{p}<0.01$ Anlamlı farklılık bulunmaktadır.

Toplumsal cinsiyet boyutları için cinsiyet sıra ortalamaları-Normal dağılım göstermeyen boyutlar

\begin{tabular}{|l|c|c|}
\hline \multicolumn{1}{|c|}{ Boyutlar } & $\begin{array}{c}\text { K } \\
\text { MeanRank }\end{array}$ & $\begin{array}{c}\text { E } \\
\text { MeanRank }\end{array}$ \\
\hline Evlilikte cinsiyet rolü* & 161,88 & 255.05 \\
\hline Eşitlikçi cinsiyet rolü* & 239.40 & 161.10 \\
\hline
\end{tabular}

Eşitlikçi CR (U:12622; p<0.01), Evlilikte CR (U:11123.5; p<0.01) <0.01. Anlamlı farklılık bulunmaktadır.

* Mann-Whitney U testi uygulanmıştır. 
Elgün, A., Yeniçeri Alemdar, M. (2017). Üniversite öğrencilerinin toplumsal cinsiyet rolleri tutumlarına yönelik bir araştırma: Ege Üniversitesi İletişim Fakültesi örneği. International Journal of Social Sciences and Education Research, 3(3), 1054-1067.

- Kadın CR, geleneksel CR, erkek CR boyutu açısından kadınlar erkeklere gore eşitlikçi tutuma daha yakın bir yapıdadır.

- Normal dağılım göstermeyen Evlilikte CR (U=11123.5 p p0.05) ve EşitlikçiCR (U=12622 p $>0.05$ ) boyutlarına yönelik tutumlarda da cinsiyete gore anlamlı bir farklıllık gözlenmiştir. Evlilikte cinsiyet rolü açısından kadınlar erkeklere göre eşitlikçi tutuma daha yakın bir yapıdadır. Eşitlikçi cinsiyet rolü açısından ise erkekler kadınlara göre eşitlikçi tutum yapısına daha yakın gözükmektedir.

H3: Demografik faktörler ve TCRTÖ'de yer alan boyutlara ilişkin tutumlarının farklılık göstermesi arasında anlamlı bir ilişki bulunmaktadır.

H3'ü test etmek için bağımsız örneklem tek yönlü varyans analizi ve kruskal-wallis H testi uygulanmıştır. TCRTÖ'de yer alan boyutlara ilişkin tutumlarda anlamlı farkın gözlendiği demografik değişken "baba mesleği” olmuştur.

TCRTÖ içinde yer alan erkek CR boyutunda ( $p\langle 0,05$ düzeyinde) anlamlı bir farklılık gözlenmiştir. Bu doğrultuda erkek cinsiyet rolü boyutunda geleneksel görüşe sahip olmada babanın mesleğine göre bir değişim izlenmiş; babası çalışmayan öğrenciler eşitlikçi tutum yapısından daha uzak öğrenciler olmuştur.

TCRTÖ'de yer alan boyutlara ilişkin tutumlarda "ailenin aylık ortalama geliri, doğum yeri, ilköğrenim bitirilinceye kadar en uzun süre yaşanılan yerleşim yeri, gelinen coğrafi bölge, aile tipi, anne-baba öğrenim durumu, anne mesleği” demografik sorularına göre anlamlı farklılıklara rastlanmamıştır $(\mathrm{p}\rangle 0,05)$.

$\mathrm{Bu}$ doğrultuda $\mathrm{H} 3$, baba mesleği demografisi dışında kabul edilmemiştir.

H4: Toplumsal cinsiyet dersini alma ve TCRTÖ'de yer alan boyutlara ilişkin tutumlarının farklılık göstermesi arasında anlamlı bir ilişki bulunmaktadır.

H4'ü test etmek amaciyla gerçekleştirilen analize göre, öğrencilerin toplumsal cinsiyet dersini almaları ile TCRTÖ boyutlarını algılamada anlamlı bir farklılığa rastlanmamıştır ( $>0.05)$

$\mathrm{Bu}$ doğrultuda $\mathrm{H} 4$, kabul edilmemiştir.

Ayrıca öğrencilerin Toplumsal Cinsiyet kavramı ile her hangi bir ders içeriğinde karşılaşıp karşılaşmadıklarını tespit etmek amacıyla, bu soruya ilişkin frekans analizi yapılmıştır. Öğrencilerin \%73'ü evet, \%25.4'ü hayır cevabını vermiştir.

Hipotezlerde yer almamakla birlikte Toplumsal Cinsiyet kavramıyla karşılaşma ve TCRTÖ boyutlarına ilişkin tutumlarda bir farklılaşma olup olmadığı da analiz edilmiştir.

Tablo 6. Toplumsal cinsiyet kavramı ile herhangi bir ders içeriğinde karşılaşma ortalama puan farkl11ıkları-Normal dağılım gösteren boyutlar

\begin{tabular}{|l|l|l|l|}
\hline Boyutlar & $\begin{array}{r}\text { Evet } \\
\text { Ort/SS }\end{array}$ & $\begin{array}{l}\text { Hayır } \\
\text { Ort /SS }\end{array}$ & sig \\
\hline Kadın cinsiyet rolü & $2.28 / 0.79$ & $0.48 / 0.48$ & $.000^{*}$ \\
\hline Geleneksel cinsiyet rolü & $1.66 / 0.74$ & $1.87 / 0.79$ & $.008^{*}$ \\
\hline Erkek cinsiyet rolü & $1.44 / 0.60$ & $1.50 / 0.64$ & .397 \\
\hline
\end{tabular}

*( $\mathrm{p}\langle 0,05)$ Anlamlı farklılık bulunmaktadır.

- Kadın CR açısından, Toplumsal Cinsiyet kavramı ile herhangi bir ders içeriğinde karşılaşan 
Elgün, A., Yeniçeri Alemdar, M. (2017). A study oriented on the communication faculty students' attitudes towards gender roles: Ege University sample. International Journal of Social Sciences and Education Research, 3(3), 1054-1067.

öğrencilerin, karşılaşmayanlara göre daha yüksek bir ortalamaya sahip olduğu gözlenmiştir. Bu durum kavram ile karşılaşanların geleneksel tutuma yakınlığını göstermektedir.

- Geleneksel CR açısından kavram ile karşılaşanlar karşılaşmayanlardan daha düşük ortalamaya sahip olmuştur. Bu durum, kavram ile karşılaşmayanların geleneksel yapıya daha yakın bir yapıda olduğunu göstermektedir.

- Normal dağılım göstermeyen boyutlar açısından anlamlı bir farklılık izlenmemiştir.

Evlilikte CR (U: 042; p 〉0.05), Eşitlikçi CR (U:134; p〉0.05).

\section{Tartışma ve sonuç}

İletişim fakültesi öğrencilerinin toplumsal cinsiyet rolleri tutumlarının Ege Üniversitesi İletişim Fakültesi Öğrencileri örneği üzerinden incelendiği bu çalışmada; öğrencilerin toplumsal cinsiyet rollerine ilişkin tutumlarının belirlenmesi ve tutumlarda farklılaşmaya yol açabilecek çeşitli değişkenler ile demografik faktörlerin neler olduğunun ortaya konması amaçlanmıştır. Öğrencilerin üniversite eğitimlerinin birinci yılında olmaları ile mezuniyet aşamasında olmalarının tutum farklılığına temel oluşturabileceği düşünülerek çalışma, 1. ve 4. sınıf öğrencilerini kapsamıştır.

$\mathrm{Bu}$ amaçla $\mathrm{H} 1$ oluşturulmuş, ancak tutumların farklılık göstermesinde anlamlı bir sonuca ulaşılamamıştır. [ ( p $>0.05)$. Eşitlikçi cinsiyet rolü (U: 31447.5; p $>0.05)$, Evlilikte cinsiyet rolü (U:31279; $p>0.05) p>0.05]$. Bu nedenle toplumsal cinsiyet rollerine ilişkin boyutların açılanmasında 1 ve 4 . sınıf öğrencileri birlikte değerlendirilmiştir.

Bu çalışma ile cevap aranan sorulardan bir tanesi de öğrencilerin TCRTÖ'de yer alan boyutlara ilişkin tutumlarının ne yönde olduğudur. Ölçek içinde yer alan 5 boyuttan ilki olan Kadın Cinsiyet Rolü açısından öğrencilerin geleneksel ve eşitlikçi tutum yapısı açısından ortada bir değer aldıkları gözlenmiştir (Ort.:2.33). Diğer dört boyutta ise; Evlilikte CR (Ort.:1.39), Geleneksel CR (Ort.:1.72), Eşitlikçi CR (Ort.:4.57- R), Erkek CR boyutu (Ort.: 1.46 ) eşitlikçi tutum yapısı gözlenmiştir.

Öğrencilerin cinsiyeti ile TCRTÖ'de yer alan boyutlara ilişkin tutumlarının yönünü ortaya koymak amacıyla $\mathrm{H} 2$ oluşturulmuştur. Tutumların cinsiyete göre farklılık göstermesinde anlamlı bir sonuca ulaşılmış ve H2 kabul edilmiştir [(p<0.01); Eşitlikçi CR (U:12622; p<0.01), Evlilikte CR (U:11123.5; $<<0.01)<0.01]$. Analiz sonucu; Kadın CR, Geleneksel CR, Erkek CR, Evlilikte $\mathrm{CR}$ açısından kadınların erkeklere göre eşitlikçi tutuma daha yakın bir yapıda olduğuna işaret etmektedir.

Bu noktaya değin yapılan analizler öğrencilerin TCRTÖ'de yer alan boyutları algılama noktasında sınıf farkı gözetmeksizin eşitlikçi tutum yapısına sahip olmakla birlikte; kadınların erkeklere göre daha fazla eşitlikçi tutum içinde olduğunu göstermiştir.

Alan yazında da dikkat çekildiği üzere toplumsal cinsiyet rollerini üreten kurumlardan olan aile yapısı, anne baba mesleği ve eğitim durumları, ayrıca öğrencilerin aileleriyle birlikte en uzun yaşadıkları yerleşim birinin niteliği ve gelinen coğrafi bölge sorularını da kapsayan demografik faktörlerin, öğrenci tutumlarındaki farklılaşma ile ilintili olacağı düşünülerek H3 oluşturulmuştur. Her bir faktör için ayrı uygulanan testler sonucunda ise anlamlı farklılığın gözlendiği tek demografik değişken, Erkek CR boyutu açısından "baba mesleği” olmuştur ( $\mathrm{p}<0.05)$. Bu doğrultuda, erkek cinsiyet rolü boyutu açısından; babası çalışmayan öğrencilerin eşitlikçi tutum yapısından daha uzak oldukları görülmüştür. Çalışma bu sonuca işaret etmekle birlikte, bunun ardında yatan 
Elgün, A., Yeniçeri Alemdar, M. (2017). Üniversite öğrencilerinin toplumsal cinsiyet rolleri tutumlarına yönelik bir araştırma: Ege Üniversitesi İletişim Fakültesi örneği. International Journal of Social Sciences and Education Research, 3(3), 1054-1067.

nedenlerin neler olabileceğinin açığa çıkarılmasında farklı veri toplama teknik ve analizlerine (derinlemesine görüşme- betimsel analiz- içerik analizi) başvurulması gerektiği düşünülmektedir. Farklılığın tek bir boyut içinde ve tek demografide gözlenmesi nedeniyle H3 kabul edilmeyecek, ancak ilerideki araştırmalar için "baba mesleği” ele alınması gereken bir konu olabilecektir.

Öğrencilerin toplumsal cinsiyet dersini alma durumlarının tutumlarda oluşturduğu farklılığı görmek amacıyla H4 oluşturulmuş ancak anlamlı bir farklılığa rastlanamamıştır (p $>0.05)$. Öğrencilerin 91'i dersi alırken, 495'i ise dersi almamıştır. Bu durumun farklılığın gözlenememesi ile ilgili olduğu düşünülerek hipotezlerde yer almasa da daha önce Toplumsal Cinsiyet kavramı ile herhangi bir ders içeriğinde karşılaşıp karşılaşmadıkları sorulmuş ve 373 evet, 130 hayır cevabı alınmıştır. Bu durumun tutumlarla ilişkisi ayrıca analiz edilmiştir. Geleneksel CR boyutu açısından anlamlı bir farklılık gözlenmiştir. Toplumsal cinsiyet kavramı ile herhangi bir ders içeriğinde karşılaşmayan öğrenciler geleneksel tutum yapısına daha yakın gözükmektedir. Toplumsal cinsiyet dersini alma ya da kavramla karşılaşma noktasında öğrenci sayısının artışıla bu konuda daha anlamlı sonuçlara ulaşılabileceği düşünülmektedir.

Bir eğitim kurumu olması ve medya-iletişim alanındaki eğitim içeriği nedeniyle iletişim fakültesi örneğinin çalışma grubu olarak seçildiği bu araştırmada; alanyazın incelemesinde; toplumsal cinsiyet rolleri araştırmalarının çalışma grubunu üniversite öğrencileri oluşturmakla birlikte iletişim fakültesi örneğinin bulunmaması bu çalışmanın önemine işaret etmektedir. Toplumsal cinsiyet rollerine ilişkin yaşama geçirilecek bundan sonraki araştırmalarda iletişim fakültesi örneklerinin çoğalması; geleceğin medya çalışanlarının içerik oluşturma kabiliyet ve olanaklarının fazlalığı nedeniyle, şimdiden değerlendirilmeli, araştırma yöntem ve veri toplama araçlarında çeşitliliğe gidilmelidir.

\section{Kaynakça}

Arıc1, F. (2011). Üniversite ögrrencilerinde toplumsal cinsiyet rollerine ilişkin algllar ve psikolojik iyi oluş. Basılmamış yüksek lisans tezi. Hacettepe Üniversitesi, Ankara.

Atış, F. (2010). Ebelik/ HemşiReliK 1. ve 4. Sinıf Öğrencilerinin Toplumsal Cinsiyet Rollerine İlişkin Tutumlarının Belirlenmesi. Basılmamış yüksek lisans tezi, Çukurova Üniversitesi Sağlık Bilimleri Enstitüsü. Adana.

Balcı, A. (2000). Sosyal Bilimlerde Araştırma Yöntem, Teknik ve İlkeler. Ankara:PegemYayınc1lık

Bekleviç, A.Ç. (2016). Bir Üniversite Hastanesi Araştırma Görevlilerinin Toplumsal Cinsiyet

Roller Tutum Ölçeği Ve Çalışma Yaşamında Toplumdal Cinsiyet Roller Algısının Değerlendirilmesi. Basılmamış, yüksek lisans tezi, Bülent Ecevit Üniversitesi Sağlık Bilimleri Enstitüsü, Zonguldak.

Bem, S. L. (1981). Gender Schema Theory: A cognitive account of sex typing. Psychological Review, 88(4), 354.

Berger, J. (1986). Görme Biçimleri. İstanbul: Metis Yayınları.

Burr, V. (2002). Gender and Social Psychology. New York: Routledge.

Büyüköztürk, Ş., (2005). Anket Geliştirme, Türk Eğitim Bilimleri Dergisi, 3(2), 133-148

Cevizci, A. (1999). Felsefe Sözlüğü. İstanbul: Paradigma Yayınları.

Child, D. (1970). The Essentials of Factor Analysis. London: Holt, Rhinehartand Winston.

Connell, R.W. (1998). Toplumsal Cinsiyet ve İktidar. İstanbul: Ayrıntı Yayınları. 
Elgün, A., Yeniçeri Alemdar, M. (2017). A study oriented on the communication faculty students' attitudes towards gender roles: Ege University sample. International Journal of Social Sciences and Education Research, 3(3), 1054-1067.

Dökmen, Z. Y. (2004). Toplumsal Cinsiyet. İstanbul: Sistem Yayıncıl1k.

Ecevit, Y. (2011). Toplumsal cinsiyet sosyolojisine başlangıç. Içinde Ecevit, Y.,

Karkıner N.(Eds.), Toplumsal Cinsiyet Sosyolojisi (2-32). Eskişehir: Anadolu Üniversitesi Yayınları.

Erdoğan, İ., Alemdar, K. (1990). Iletişim ve Toplum: Kitle İletişim Araçlarında Tututcu ve Değişimci Yaklaşımlar. Ankara: Bilgi Yayınevi.

Erdoğan, İ., Alemdar, K. (2002). Öteki Kuram. Ankara: Erk Yayınları.

Fichter, J. (2002). Sosyoloji Nedir. Ankara: Anı Yayıncılık.

Giddens, A. (2012). Sosyoloji. İstanbul: Kırmızı Yayınları.

Girginer, U. (1994). Türk Toplumunda Cinsiyet Rolleri Algısı. Basılmamış yüksek lisans tezi, Ege Üniversitesi, Sosyal Bilimler Enstitüsü, İzmir.

Hooks, B. (2016). Feminizm Herkes İçindir. İstanbul: BGST Yayınları.

Mc Hugh, Frieze, I. H. (1997). The measurement of gender-role attitutes: A review and commentary. Psychology of Woman Quarterly, 21, 1-16.

Nunnally, J.C. (1978). Psychometrictheory. New York: McGraw-HillBookCompany.

O’Neil, J.N., Helms, B.J., Gable, R.K., David, L.\& Wrightsman, L. S. (1986). Gender roles conflict scale: College men's fear of femininity. Sex Roles, 14(5/6), 335-350

Öngen, B., Aytaç, S. (2013). Üniversite öğrencilerinin toplumsal cinsiyet rollerine ilişkin tutumları ve yaşam değerleri ilişkisi. Sosyoloji Konferansları. no:48(2). 1-18.

Pilcher, J., Whelehan, I. (2004). 50 Keys Concepts in Gender Studies. London: Sage Publishing

Türkmenoğlu, D. (2016). Hemşirelik Öğrenimi Gören Birinci ve Son Sınıf Üniversite Öğrencilerinin Toplumsal Cinsiyet Rollerine Ilişkin Tutumlarının Belirlenmesi. Basılmamış yüksek lisans tezi, Mersin Üniversitesi Kadın Çalışmaları Anabilim Dalı, Mersin.

Ural, A \&Kılıç, İ. (2011). Bilimsel Araştırma Süreci ve SPSS ile Veri Analizi. Ankara: DetayYayıncılık.

Zeyneloğlu, S. (2008). Ankara'da Hemşirelik Öğrenimi Gören Üniversite Öğrencilerinin Toplumsal Cinsiyet Rollerine İlişkin Tutumları. Doktora tezi, Hacettepe Üniversitesi, Sağlık Bilimleri Enstitüsü. Ankara. 
Elgün, A., Yeniçeri Alemdar, M. (2017). Üniversite öğrencilerinin toplumsal cinsiyet rolleri tutumlarına yönelik bir araştırma: Ege Üniversitesi İletişim Fakültesi örneği. International Journal of Social Sciences and Education Research, 3(3), 1054-1067.

\section{Extended abstract in English}

Sex highlights the genetic, physiological and biological characteristics that an individual possesses by birth. It is evaluated in two categories; female and male. gender, on the other hand, is defined as a concept that involves the expectations of society and culture from gender categories and meanings attributed to these categories. gender contains division of labour, behaviours and roles based on gender. While conventional meanings attributed to gender in society constrain women to certain stereotypic roles, more liberated and independent roles are attributed to men as a gender. There are various institutions, structures and factors that construct gender roles. Family, education, social circles, street and politics are the fields where gender roles are produced. Another establishment that produces gender roles is media.

The ties between gender and media have been on the agenda as a controversial field since the 1960s. In the focus of the discussions, it is argued that the representation system in media and the structure of media formed depending on the patriarchal ideology, resulting in gender inequality. Awareness of the media professionals, who create media texts, with regard to gender equality, their gender perception and attitudes towards gender all have an influence on media and contents.

This study is designed to measure media and communication students' attitudes towards gender roles. The attitudes of media and communication faculty students who have a higher prospect of being employed in various parts of the media industry, is thought to be influential in removing the sexist perspectives in the media industry, in providing equality with regard to employment and in transforming the representation system that formed in the framework of stereotypical judgments. In this context, Communication Faculty students' attitudes towards gender roles are going to be analyzed by using "Attitudes towards Gender Roles Scale", developed by Simge Zeyneloğlu in 2008. With the help of a questionnaire that is going to be applied to Ege University Communication Faculty first and final year students, it is aimed to reveal whether the educational year they are in, their demographic characteristics and the courses they take, have an effect on their perspectives of and attitudes towards traditional male/female gender roles.

Hypothesis for the research were formed as below.

$\mathrm{H} 1$ : There is a meaningful relationship between the students' attitudes showing difference regarding the dimensions of ASGRS and them being at their first or senior year

$\mathrm{H} 2$ : There is a meaningful relationship between the students' gender and their attitudes regarding the dimensions of ASGRS differing.

H3: There is a meaningful relationship between the demographic factors and attitudes regarding the dimensions of ASGRS differing

H4: There is a meaningful relationship between taking the gender course and attitudes regarding ASGRS dimensions differing

In the analysis made, $\mathrm{H} 1$ and $\mathrm{H} 4$ were confirmed. Therefore, in the analysis to be applied next, first year and senior students were evaluated together without considering the class difference. A meaningful difference was reached in $\mathrm{H} 2$; as for $\mathrm{H} 4$, the only demographic varient observed regarding the attitudes towards the dimensions of ASGRS was "the father's job".

The average values and attitudes of students regarding the dimensions of ASGRS were directed as follows: 
Elgün, A., Yeniçeri Alemdar, M. (2017). A study oriented on the communication faculty students' attitudes towards gender roles: Ege University sample. International Journal of Social Sciences and Education Research, 3(3), 1054-1067.

Female Gender Role Dimension: The students sub dimension average of "female gender role" was realized as 2.33 . We can talk about a middle scale value accomplished by the students by means of conventional and equalitarian strucure.

Gender Role Dimension in Marriage: Students had an average point of 1.39 in this subdimension. At this point, it is observed that students show an equalitarian attitude regarding the gender role in marriage.

Conventional Gender Role Dimension: Students' average regarding this dimension is 1.72 . Score indicates that students are close to the equalitarian attitude regarding the conventional gender role.

Equalitarian Gender Role Dimension: In contrary to other dimensions, the closeness of the values to 1 to be taken from this dimension are considered as conventional, closeness to 5 is regarded as an equalitarian attitude indicator. The students average value regarding this dimension is 4.57 and students have an equalitarian attitude.

Male Gender Role Dimension: The student average for this dimension was realized as 1.46. At this point, students having an equalitarian attitude regarding the male gender role, can be spoken of.

In this research, establishing the students' attitudes regarding gender roles, a qualitative research design, based on the independent variants where meaningful differences are observed, can be useful in terms of examining the matter of gender roles 